American Journal of

Health, Medicine and Nursing Practice (AJHMN)

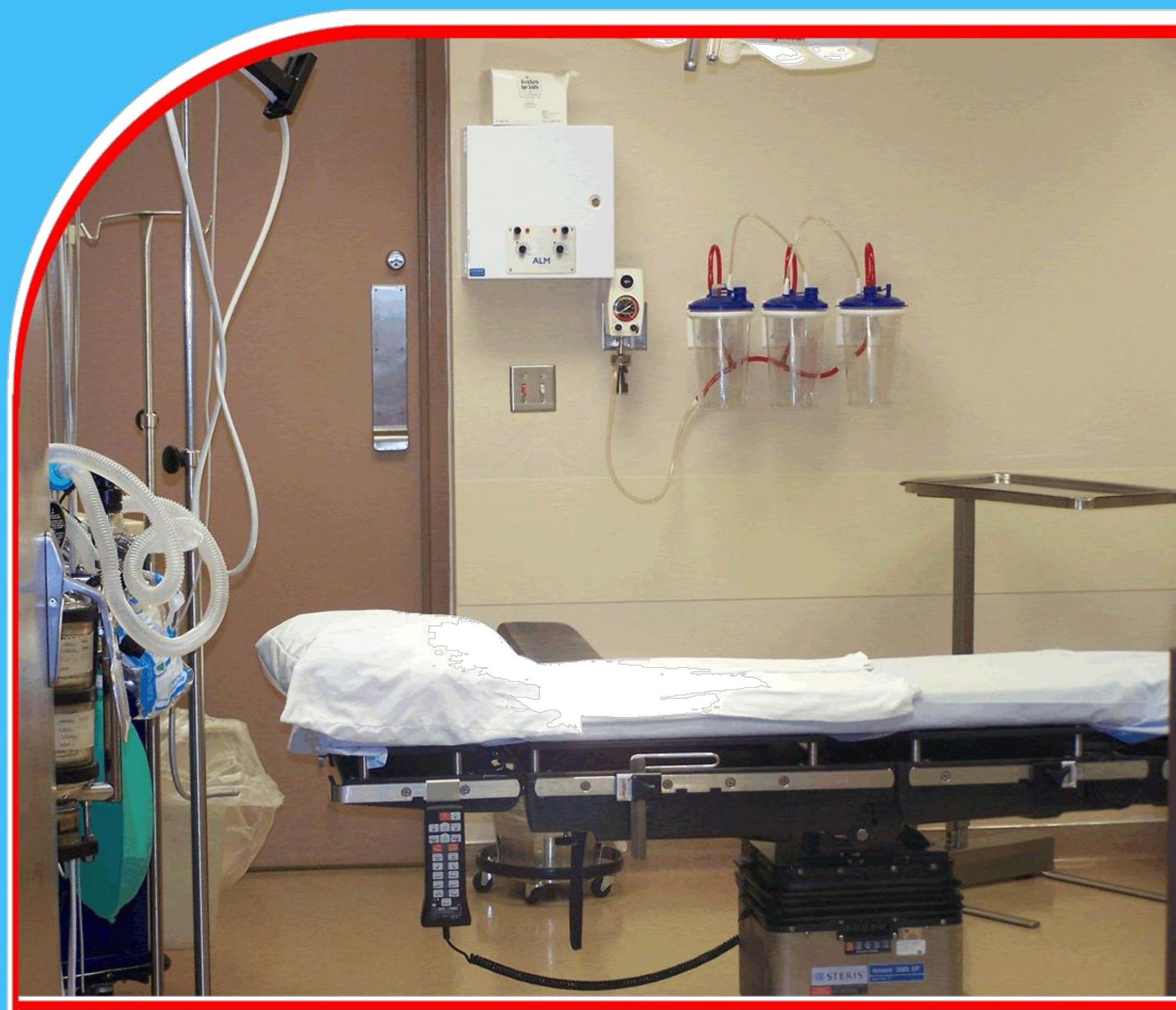

THE INFLUENCE OF SOCIAL ECONOMIC FACTORS ON THE INCREASING INCIDENCES OF BURNS AMONG ADULT PATIENTS ADMITTED IN THE KENYATTA NATIONAL HOSPITAL BURNS UNIT Nelly C. Amakobe, Dr. Makori Moronge

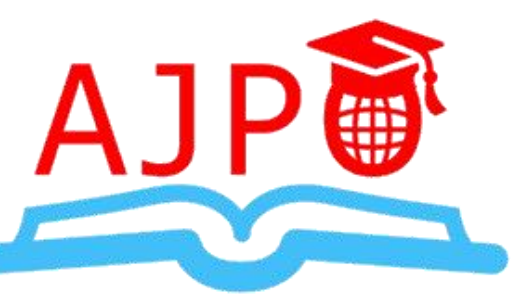




\title{
THE INFLUENCE OF SOCIAL ECONOMIC FACTORS ON THE INCREASING INCIDENCES OF BURNS AMONG ADULT PATIENTS ADMITTED IN THE KENYATTA NATIONAL HOSPITAL BURNS UNIT
}

\author{
${ }^{1 *}$ Nelly C. Amakobe \\ ${ }^{1 *}$ Post Graduate Student, School of Nursing \\ Kenya Methodist University \\ *Corresponding Author's Email: \\ ${ }^{2}$ Dr. Makori Moronge \\ Senior Lecturer, School of Nursing
}

\begin{abstract}
Purpose: The purpose of the study was to establish the influence of social economic factors on the increasing incidences of burns among adult patients admitted in the Kenyatta National Hospital Burns Unit.

Methodology: The population of this research consisted of all patients in the burns unit at Kenyatta hospital. The study used primary data in particular used questionnaires. The questionnaire consisted of structured closed ended statements. Data was analyzed using Statistical Package for Social Sciences (SPSS) mainly by use of descriptive statistics. Descriptive statistics included mode, mean, median, standard deviation. Data was presented by use of graphs, pie charts and tables.

Results: The study findings indicated that there has been an increase in number of patients with burns which is associated with various social economic factors causing the increased incidences among the patients.

Unique contribution to theory, practice and policy: From the study findings the researcher recommend that it's important to educate the citizens in order to make them more aware of the dangers associated with various factors such as illegal electricity connection and lack of access roads. In doing this more cases of fire would be reduced and reduce loss of lives and property in more fire prone areas. The study also recommends that the Government through the Ministry of Public Health and Sanitation should impart knowledge related to the burns especially on how people can take preventive measures and emergency measures against fire outbreak.
\end{abstract}

Keywords: social economic factors, incidences of burns, adult patients, Kenyatta National Hospital Burns Unit 


\subsection{INTRODUCTION}

Burn is a type of injury to flesh caused by heat, electricity, chemicals, light, radiation or friction (Saunders, 2007). The extent of the injury depends on the degree of heat and length of time in contact with the heat (Burn injury model, 2009). A burn is an injury that cannot cause disability, if proper treatment is provided on time. On the contrary, if the injury is inadequately treated or not following standard rules and principles, burn injury can seriously threaten the patient's life, and lead to complications such as disabilities that increase burden to family, community and the nation may arise.

Worldwide burn injury is a problem, it causes intense pain and long term morbidity is often a significant problem for burn a survivor that creates suffering for the individual as well as for family and community. The causes of burn injuries are intense heat or flame, scalds and radiation burns (from the sun's ultraviolet rays), chemical burns and electrical burns. (Chaliseet al.,2008; Lawrence, 2008). Developing countries have a high incidence of burn injuries, creating a formidable public health problem.

The incidence of burns varies across countries, populations, and time the severity of a burn depends on the degree of heat, duration of exposure, and thickness of the involved skin (Sen, Greenhalgh \& Palmieri, 2010). The treatment of burns requires a multidisciplinary approach; it varies depending on the psychological and physiological status of the patient. The main components of treatment are surgical intervention (early excision/skin grafting), volume therapy, the treatment of sepsis and multi-organ failure, nutrition, and rehabilitation (Evers, Bhavsar \& Mailander, 2010). The quality of nursing is also of great importance for successful outcomes (Osborn, 2003). Burns are global Public Health problems, accounting for an estimated 195,000 deaths annually. World Health organization (WHO) estimated that 43000 people die of burns in Africa every year with a rate of 6.1 per 100,000.

Burn injuries are common in Kenya and are a leading cause of morbidity and mortality rates, including prolonged hospitalization, disfigurement and disability, often with resulting stigma and rejection. Such injuries impose substantial medical, social, economic and social burden on society and victims of families. Patients often develop numerous surgical procedures over a long period of hospitalization and some require readmission for reconstructive surgery.

Kenyatta National Hospital $(\mathrm{KNH})$ in Nairobi is the oldest hospital in Kenya. Founded in 1901 with a bed capacity of 40 as the Native Civil hospital, it was renamed the King George VI in 1952. It is currently the largest referral and teaching hospital in the country.

KNH has turned 112 years and it had its Centenary Celebration in 2001. The Hospital was built to fulfill the role of being a National Referral and Teaching Hospital, as well as to provide medical research environment.

$\mathrm{KNH}$ is the only hospital in Kenya that has a Burns unit that caters for patients with burn injuries from all over the country. The burns unit is well equipped and the nurses provide health care services in collaboration with the plastic surgeons, psychologists, physiotherapists, occupational therapists and nutritionists. All patients with severe burns from other hospitals in the country are referred to $\mathrm{KNH}$ for proper treatment. It admits both adults and children in the same unit; the unit has a bed capacity for 21 patients. The patients are admitted in the Burns unit in their acute phase, they are managed until when they are stable to be transferred to another ward (ward 4D) which has a large bed capacity of 100 patients to continue with management.

\subsection{Problem Statement}

Burn injuries among adults have become a major problem in Kenya today leading to, prolonged hospital stay, disfigurement, disability and increased mortality rates. In the 2011- 
2012 the number of adult patients admitted in $\mathrm{KNH}$ with burn injuries is three times more than the past years.

Most of the adult burns are caused by flames 66\% (including petrol, kerosene, gas, candles and falling into fire), $21 \%$ caused by scalds, $10 \%$ by electricity and $10 \%$ by chemicals.

The bed capacity in the burns unit and the burns ward is no longer able to cater for the increased number of admissions in the hospital. To an extent whereby during such crisis the emergency wards are used to admit some of the cases.

Patients are at risk of many complications which include- infections, decrease tissue perfusion, acute renal failure, contracture and death (Pham, Cancio\&Gibran, 2008).

Therefore, the major objective of this study is to address the factors associated with the increasing incidences of burns among adult patients admitted in Kenyatta National Hospital Burns Unit. Burn injuries are common in Kenya yet evidence shows that prevention strategies can work; therefore there is an urgent need to address factors associated with increased incidence of burns among adults admitted at KNH Burns unit.

\subsection{Research Objective}

To establish the influence of social economic factors on the increasing incidences of burns among adult patients admitted in the Kenyatta National Hospital Burns Unit.

\subsection{LITERATURE REVIEW}

\subsection{Empirical Review}

Some evidence has linked a number of familial factors to burn injuries amongst children. It has been documented globally that poor socio-economic circumstances increase the risk of paediatric burn injuries (Cubbins, LeClere and Smith, 2000; Van Niekerk, Reimers and Laflamme, 2006; Forjouh, 2006; Edelman, 2007; van Niekerk, 2007; Peck et al, 2008). The World Health Organisation (WHO) states that over 90\% of fatal fire-related burns occur in low and middle-income countries. Over $98 \%$ of deaths from fire and burns occur in developing nations, which are least able to provide the resources for care or the community support for rehabilitation (Peck et al, 2008).

Ombati, Ndaguatha and Wanjeri (2013) did a study on the risk factors for kerosene stove explosion burns seen at Kenyatta National Hospital in Kenya. The study was a prospective longitudinal descriptive study carried out at the Kenyatta National Hospital. Forty-eight patients who met the inclusion criteria were recruited into the study over a period of 6 months from November 2010 to April 2011 and the data was collected using a structured questionnaire. The analysis, using SPSS version 17.0 was done by associating occurrence of injury to: age, sex, socioeconomic status and level of education of patient. Results indicated that the mean age of patients who sustained kerosene stove explosion burns was 23.6 years (SD \pm 11.7 ) with the commonest age group being 20-39 years. More females were affected than males by a ratio of 7:3 and ninety two percent of those who sustained these burns were either from poor or lower middle socio-economic class. Stove explosions occurred mainly during cooking and when kerosene refill was being done. Most of the patients (63\%) reported having bought kerosene from fuel vendors and almost all explosions were caused by the wick type of stove $(98 \%)$. The study concluded that young females from poor socioeconomic background were found to be at a higher risk for kerosene stove explosion burns. The wick stove is a common cause of burns especially when users unwittingly refill it with kerosene when already lit resulting in an explosion. Prevention can be done through evidence based public health education targeting the groups at risk and enactment of relevant laws.

Dongo, Irekpita, Oseghale, Ogbebor, Iyamu and Onuminya (2007) did a five-year review of burn injuries in Irrua. The management of burns remains a challenge in developing countries. 
A total of 72 patients admitted for burns between January 1st, 2002 and December 31st, 2006 at the Irrua specialist teaching hospital were studied retrospectively. Sources of information were the case notes and operation registers. Data extracted included demographics as well as treatment methods and outcome. The results revealed male to female ratio of 2.1:1. Over 50\% of the injuries occurred at home. There was a seasonal variation with over $40 \%$ of injuries occurring between November and January. The commonest etiologic agent was flame burn from kerosene explosion. There were 7 deaths in the series. Burns are preventable. The study recommended adequate supply of unadulterated petroleum products and establishment of burn centers.

International and local studies have linked a number of factors to the occurrence of burns amongst children (Werneck and Reichenheim, 1997; Delgado et al, 2002; Van Niekerk, Rode and Laflamme, 2004, van Niekerk, 2007). These include family education, poor living conditions and overcrowding. Environmental conditions do contribute to the occurrence of injuries, such as the use of various fuels for heating and cooking, and various heating and cooking appliances (van Niekerk, 2007). Cultural and religious traditions may also increase the risk of injury, such as the long flowing, highly flammable cotton robes commonly worn by African children. Clothing fires were the cause of $25 \%$ of all flame burns in Zaire, Africa (Kalayi \& Muhammad, 1994).

Results from a study done in Karachi, India, showed that socio-economic factors such as overcrowding in poor housing conditions, lack of proper medical facilities and ignorance were found to be the most important cause of burns (Kildal, Willebrand, Anderson, Gerdin and Ekselius, 2004). Alcohol consumption and cigarette smoking amongst parents or other adults is also thought to be an injury risk (Boukind, Chafiki, Terrab, Alibou, Bahechar and Zerouali, 1995; Werneck and Reichenheim, 1997). In South Africa, the African group has been reported to have lower income levels, literacy rates and overall health status and higher levels of overcrowding in housing. This results in a lower educational level of mothers, lower socio-economic status of the families, and psycho-stress in the families. These have all been linked to an increased risk of paediatric burn injuries (Van Niekerk, Rode and Laflamme, 2004).

Burn injuries that occur in the home account for over $80 \%$ of all childhood burn injuries in developed countries and over $90 \%$ of all childhood burn injuries in developing countries (Lari, 2002). Electrical appliances, space heaters, furnaces, fireplaces, kitchen stoves and hot plates, cigarettes, matches and lighters, faulty or outdated wiring and candles are all examples of potential sources of fire in the home. The ignitable fuels in homes include mattresses, furniture, flammable liquids, propane, natural gas, drapes and carpets (McLoughlin \& McGuire, 1990).

In South Africa burns from fire, paraffin stove explosions and torched homes are common with the increasing urban informal settlement (Lakhoo, 1995). Burn injuries that occur in informal dwellings are often severe. These structures are commonly referred to as 'shacks' and have occurred as a consequence of urban migration and are common in major cities of South Africa (Godwin et al, 1996). These structures are built in informal settlements without proper town-planning, with cramped living quarters; they are made of highly combustible and toxic materials such as painted wood or plastics and are assembled close to one another (Peck, Kruger, van der Merwe, Godakumbura and Ahuja, 2008).

A significant number of South African families live in single room shacks, traditional dwellings and mud huts, which have no electricity and therefore have to use alternative means for lighting and cooking such as gas stoves, primus paraffin stoves as well as fire bolas. Poverty affects the choice, quality and condition of appliances as well as the fuel-type 
used (Peck et al, 2008). The cramped living spaces suggest that children are much more likely to be present when adults are cooking and heating water. The dangers of storing flammable substances and primus paraffin stoves have been recognized (Hudson, Rode and Bloch, 1994; Forjuoh, 2006). These stoves and flammable substances are prone to exploding or falling over and causing fires, and such accidental fires have been known to occur among people of poor social circumstances (Hudson, Rode and Bloch, 1994; Gupta, Bansal, Gupta and Goil, 1996; Forjuoh, 2006; Frenkel, 2008). The occurrence of burn injury in children is highly influenced by aspects of the local environment, such as close proximity of the shacks to one another leading to fires spreading rapidly, causing extensive damage and injury (Godwin et al, 1996; Van Niekerk, 2007).

\subsection{RESEARCH METHODOLOGY}

This study adopted a descriptive design. This descriptive research design was preferred because the study needed to establish the demographic factors associated with increasing incidence of burns among adult patients admitted in the Kenyatta national hospital burns unit. The study targeted a population of all adult patients with burns admitted at Kenyatta National Hospital. Kenyatta national hospital admits around 150 adults per month hence the target population was 150 patients. A sample size of 108 respondents was determined by the fisher et al, (2003) formula for small population. The study used simple random sampling in selecting the respondents for the study. In this study primary data was collected using a structured questionnaire, since it is easier to administer, analyze and economical in terms of time and money. The researcher used a questionnaire as a data collection tool. The questionnaire comprised of both open and closed ended questions. After data was collected, it was prepared in readiness for analysis by editing, handling blank responses, categorizing and keying into Statistical Package for Social Sciences (SPSS) computer software for analysis. SPSS was used to produce frequencies, descriptive and inferential statistics which helped to derive conclusions and generalizations regarding the population.

\subsection{RESULTS AND DISCUSSIONS}

\subsection{Response Rate}

A total of 69 responses/Questionnaires were received out of a possible 108 Questionnaires from the respondents. This was a response rate of $63.8 \%$.According to Mugenda and Mugenda (2003), a response rate of $50 \%$ or more is adequate. Babbie (2004) also asserted that return rates of 50\% are acceptable to analyze and publish, $60 \%$ is good and $70 \%$ is very good.

Table 1: Response Rate

\begin{tabular}{lcc}
\hline Response & Total & Percent \\
\hline Returned & 69 & $63.8 \%$ \\
Unreturned & 39 & $36.2 \%$ \\
Total & 108 & $100 \%$ \\
\hline
\end{tabular}

\subsection{Descriptive Statistics}

\subsubsection{Type of House}

The respondents were asked to indicate the type of a house they household lived. Results are presented in table 2 below. 
American Journal of Health, Medicine and Nursing Practice

ISSN xxxx-Xxxx (Paper) ISSN XXXX-XXX (Online)

Vol.1, Issue 1 No.1, pp 91-103, 2016

www.ajpojournals.org

Table 2: Type of House

\begin{tabular}{lcc}
\hline Type of House & Frequency & Percent \\
\hline Permanent building & 7 & 10.1 \\
Semi-permanent & 34 & 49.3 \\
Temporary & 28 & 40.6 \\
Total & 69 & 100
\end{tabular}

As illustrated in table 2, the study findings revealed that $49.3 \%(n=34)$ of the respondents indicated that they lived in semi-permanent houses, while $40.6 \%(n=28)$ of the respondents indicated that they lived in temporary and $10.1 \%(\mathrm{n}=7)$ indicated that they lived in permanent houses.

\subsubsection{Number of Rooms}

The study sought to find out the number of rooms that were in the main house of the respondents. The study findings are presented in figure 1 below.

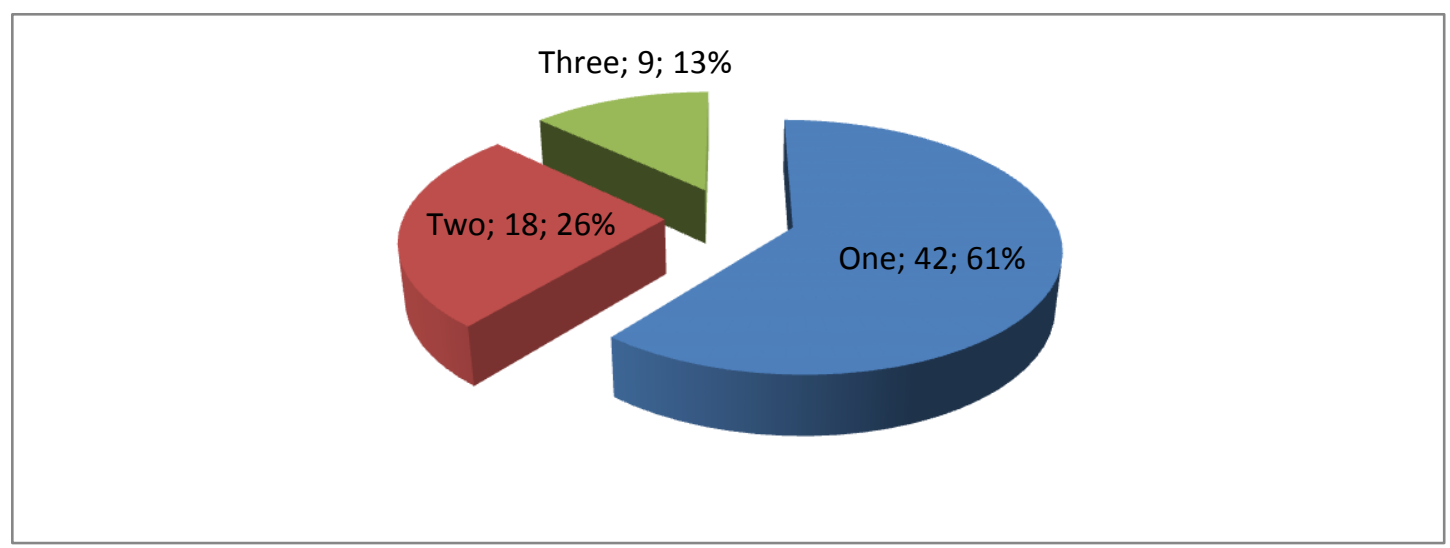

\section{Figure 1: Number of Rooms}

As illustrated in figure 1, results revealed that $61 \%(n=42)$ of the respondents lived in single rooms, while $26 \%(\mathrm{n}=18)$ indicated their houses had two rooms and $13 \%(\mathrm{n}=9)$ indicated their main house had three rooms.

\subsubsection{Number of People}

The study sought to find out the number of people who lived in the main house. Results are presented in figure 2 below.

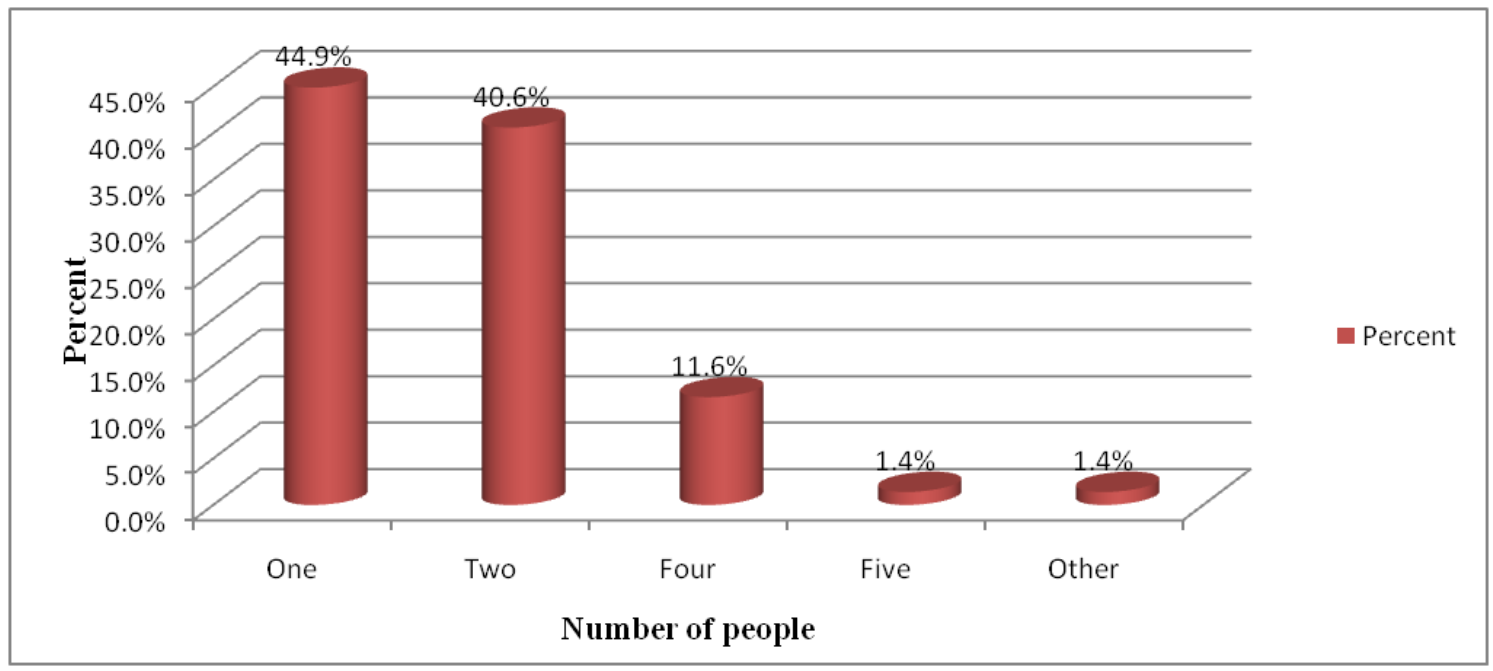




\section{Figure 2: Number of People}

As illustrated in figure 2, results revealed that $44.9 \%(n=31)$ of the respondents were staying alone in their houses, while $40.6 \%(\mathrm{n}=28)$ indicated two people lived in the house and $11.6 \%$ $(n=8)$ indicated four people lived in the house. One point four percent of the respondents indicated the house they lived in had five people in it and another 1.4\% (1) indicated others which mean that the house hosted more than five people and to be precise seven.

\subsubsection{Type of Fuel}

The study sought to find out the type of fuel the respondents used mainly for cooking in their homes. Results are presented in figure 3 below.

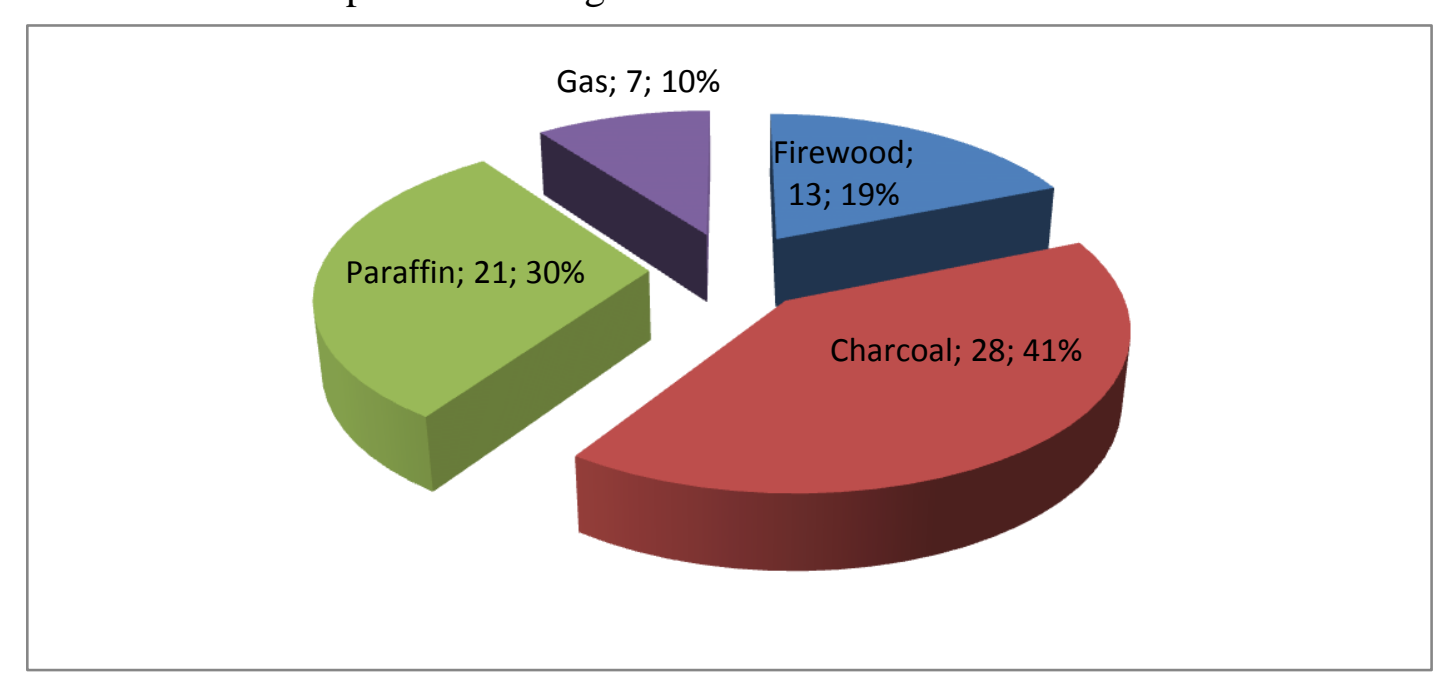

\section{Figure 3: Type of Fuel}

Figure 3 reveals that $41 \%(n=28)$ of the respondents indicated that they used charcoal, while $30 \%(n=21)$ they used paraffin and 19\% $(n=13)$ they used firewood. However, only 10\% $(\mathrm{n}=7)$ of the respondents used gas.

\subsubsection{Place of Cooking}

The respondents are asked to indicate the place where they cooked their meals from. The study findings are presented in table 4.5 below.

\section{Table 3: Place of Cooking}

\begin{tabular}{lcc}
\hline Place of Cooking & Frequency & Percent \\
\hline Inside the house & 69 & 100 \\
\hline A
\end{tabular}

As illustrated in table 3, all the respondents indicated that they cooked their food inside the house.

\subsubsection{Type of Lighting}

The respondents were asked to indicate the type of lighting they use in their houses. Results are presented in figure 4 below 


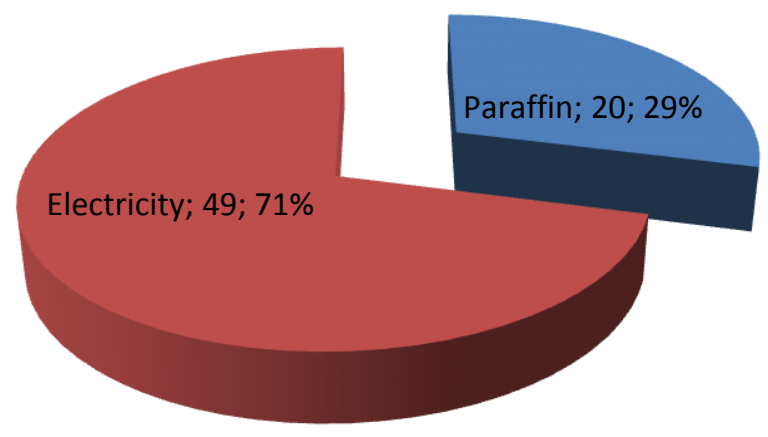

\section{Figure 4: Type of Lighting}

As illustrated in figure 4, the study findings indicated that $71 \%(\mathrm{n}=49)$ of the respondents used electricity and $29 \%(n=20)$ indicated they were using paraffin for lighting.

\subsubsection{Members Take Alcohol}

The study sought to find out if any member of their household takes alcohol. The study findings are presented in table 5 below

Table 5: Members Take Alcohol

\begin{tabular}{lcc}
\hline Member take Alcohol & Frequency & Percent \\
\hline No & 28 & 40.6 \\
yes & 41 & 59.4 \\
Total & 69 & 100 \\
\hline
\end{tabular}

Table 5 shows that $59.4 \%(n=41)$ of the respondents indicated that they had members who took alcohol and $40.6 \%(n=28)$ indicated that none of their house hold members took alcohol.

\subsubsection{Access Roads}

The respondents were asked to indicate whether they are access roads in their area where a fire engine can pass. Results are presented in figure 6 below

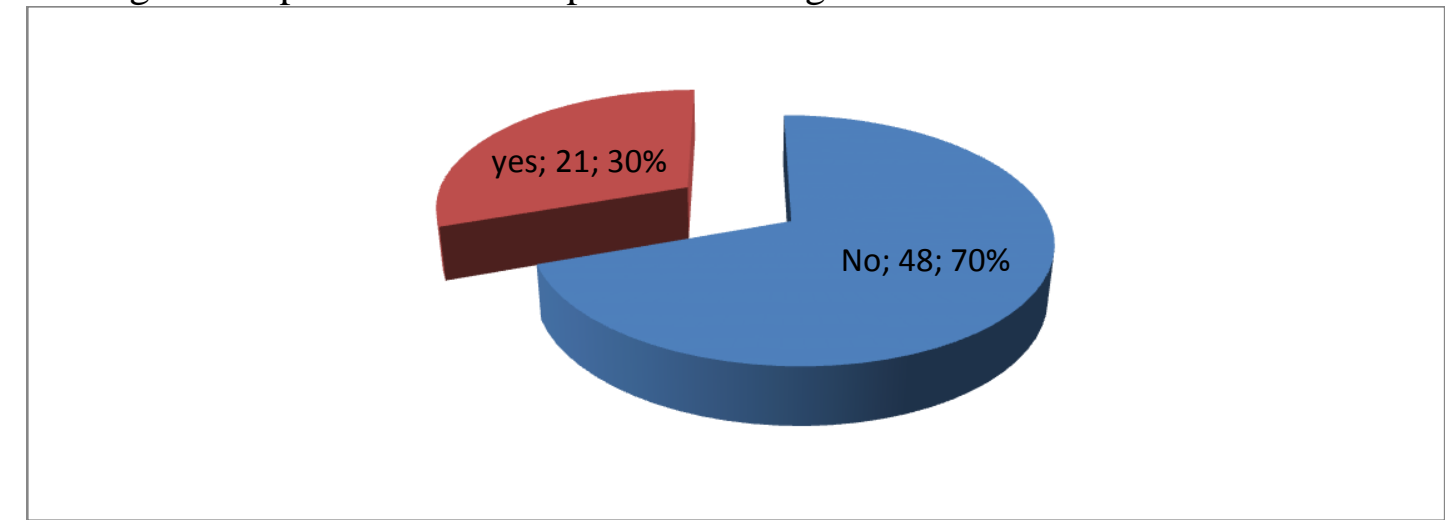

\section{Figure 6: Access Roads}

As illustrated in figure 6 , results revealed that $70 \%(\mathrm{n}=48)$ indicated that there were no access roads for fire engines to pass and $30 \%(n=21)$ indicated that there were accessible roads where the fire engines could pass. 


\subsection{Inferential Statistics}

Assessment of socio- economic factors on incidences of burns indicated that number of rooms, number of people, type of fuel and type of lighting were among the most significant factors related with incidences of burns. This was supported by $((\chi 2(1)=30.750, \mathrm{P}<0.000)$ $\left((\chi 2 \quad(1)=17.066, \mathrm{P}<0.002)\left(\left(\chi^{2}(1)=28.072, \mathrm{P}<0.000\right)((\chi 2 \quad(1)=15.052, \mathrm{P}<0.000)\right.\right.$ respectively. Type of house was not a significant factor in incidences of burns $((\chi 2)(1)=$ 5.360, $\mathrm{P}=0.069$ ).

Table 6: Relationship between socio-economic factors and incidences of burns

\begin{tabular}{|c|c|c|c|c|}
\hline & & cidenc & ourns & \\
\hline & & Yes & No & Chi-square \\
\hline Type of house & Permanent building & 7 & 0 & \\
\hline & Semi-permanent & 27 & 7 & \\
\hline & Temporary & 27 & 1 & $5.360(\mathrm{p}=0.069)$ \\
\hline No. of Rooms & One & 41 & 1 & \\
\hline & Two & 17 & 1 & \\
\hline & Three & 3 & 6 & $30.750(p=0.000)$ \\
\hline Number of people & One & 27 & 4 & \\
\hline & Two & 27 & 1 & \\
\hline & Four & 7 & 1 & \\
\hline & Five & 0 & 1 & \\
\hline & Other & 0 & 1 & $17.066(\mathrm{p}=0.002)$ \\
\hline Type of fuel & Firewood & 6 & 7 & \\
\hline & Charcoal & 27 & 1 & \\
\hline & Paraffin & 21 & 0 & \\
\hline & Gas & 7 & 0 & $28.072(\mathrm{p}=0.000)$ \\
\hline Type of Lighting & Paraffin & 13 & 7 & \\
\hline & Electricity & 48 & 1 & $15.052(\mathrm{p}=0.000)$ \\
\hline Member take alcohol & No & 27 & 1 & \\
\hline & Yes & 34 & 7 & $2.959(\mathrm{p}=0.085)$ \\
\hline Access roads & No & 41 & 7 & \\
\hline & Yes & 20 & 1 & $1.375(\mathrm{p}=0.241)$ \\
\hline
\end{tabular}

\subsection{DISCUSSION CONCLUSIONS AND RECOMMENDATIONS}

\subsection{Discussion}

About $49.3 \%(n=34)$ of the respondents indicated that they lived in semi permanent houses, while $40.6 \%(n=28)$ of the respondents indicated that they lived in temporary and $10.1 \%$ $(n=7)$ indicated that they lived in permanent houses. $61 \%(n=42)$ of the respondents lived in single rooms, while 26\% $(n=18)$ indicated their houses had two rooms and $13 \%(n=9)$ indicated their main house had three rooms. In addition, $44.9 \%(n=31)$ of the respondents were staying alone in their houses, while $40.6 \%(n=28)$ indicated two people lived in the house and $11.6 \%(n=8)$ indicated four people lived in the house. One point four percent of the respondents indicated the house they lived in had five people in it and another $1.4 \%$ (1) indicated others which mean that the house hosted more than five people and to be precise seven. About $41 \%(n=28)$ of the respondents indicated that they used charcoal, while $30 \%$ 
$(n=21)$ they used paraffin and $19 \%(n=13)$ they used firewood. However, only $10 \%(n=7)$ of the respondents used gas. All the respondents indicated that they cooked their food inside the house while $71 \%(n=49)$ of the respondents used electricity and $29 \%(n=20)$ indicated they were using paraffin for lighting and $59.4 \%(n=41)$ of the respondents indicated that they had members who took alcohol and $40.6 \%(n=28)$ indicated that none of their house hold members took alcohol. Finally, $70 \%(\mathrm{n}=48)$ indicated that there were no access roads for fire engines to pass and $30 \%(n=21)$ indicated that there were accessible roads where the fire engines could pass.

Assessment of socio- economic factors on incidences of burns indicated that number of rooms, number of people, type of fuel and type of lighting were among the most significant factors related with incidences of burns. This was supported by $((\chi 2(1)=30.750, \mathrm{P}<0.000)$ $((\chi 2)=17.066, \mathrm{P}<0.002)((\chi 2(1)=28.072, \mathrm{P}<0.000)((\chi 2(1)=15.052, \mathrm{P}<0.000)$ respectively. This implies that number of rooms, number of people, type of fuel and type of lighting influenced incidence of burns among the respondents.

The findings concur with those in Abu, Ragheb, Qaryoute and El-Muhtseb (2005) who argued that socio-cultural factors are among the major causes of different sex predisposition of burn injury in developing countries like India compared to other developed nations. On the other hand, the male predominance in the younger age group (5-10 years) might be explained by the inquisitive and exploring nature of boys of this age. This finding also concurs with other reports from different countries such as Duggan and Quine (2002) who retaliates that with respect to the place where the burn injury occurred, the majority of burns $(91.4 \%)$ occurred in the home. This figure is comparable to other reports from developing countries. However, figures from industrialized countries are clearly lower than those reported from developing countries. This may be due to the relatively higher percentage of occupational and recreational burns or due to better home safety with safer cooking and heating devices in industrialized countries

\subsection{Conclusions}

There has been an increase in number of patients with burns which is associated with various socio-economic factors causing the increased incidences among the patients. Specifically, poverty, overcrowding, having more than 3 children in the house, illegal electricity connection, lack of access roads and solid waste accumulation were identified as significant risk factors associated with injury in general. It can also be concluded that demographics factors also led to increased incidences of burns due to low education and occupation hence forcing people to live in challenging areas.

\subsection{Recommendations}

From the study findings the researcher recommend that it's important to educate the citizens in order to make them more aware of the dangers associated with various factors such as illegal electricity connection and lack of access roads. In doing this more cases of fire would be reduced and reduce loss of lives and property in more fire prone areas.

\subsection{Areas for Further Studies}

A study looking at demographics and socio-economics of the population being affected by burn injuries in rural settings and comparing this data to urban settings.

\section{REFERENCES}

Boukind, E., Chafiki, N., Terrab, S., Alibou, F., Bahechar, N. \& Zerouali, N. (1995). Aetiology of burn injuries in childhood in Casablanca, Morocco: epidemiological data and preventative aspects, Burns 21 (5): 349 - 351 
Cubbin, C., LeClere, F., \& Smith, G. (2000). Socioeconomic status and injury mortality: individual and neighbourhood determinants, Journal of Epidemiological Community Health 54: 517 - 524

Delgado, J., Ramirez-Cardich, M., Gilman, R., Lavarello, R., Dahodwala, N., Bazan, A., Rodriguez, V., Cama, R., Tovar, M. \& Lescano, A. (2002). Risk factors for burns in children: crowding, poverty and poor maternal education, Injury Prevention 8: 38 41

Dongo, A.E., Irekpita, E.E., Oseghali, L.O., Ogbebor, C.E., Iyamu, C.E., Onuminya, J.E. (2007): A five-year review of burn injuries in Irrua. BMC Health Serv Res, 7:171.

Edelman, L. ( 2007 ). Social and economic factors associated with the risk of burn injury, Burns 33: 958 - 965

Forjuoh, S. (2006). Burns in low- and middle-income countries: A Review of available literature on descriptive epidemiology, risk factors, treatment and prevention, Burns 32: $529-537$

Frenkel, L. (2008). A Support Group for parents of burned children: A South African Children's Hospital Burns Unit, Burns 34: 565 - 569

Godwin, Y., Hudson , D. \& Bloch, C. (1996). Shack fires: a consequence of urban migration, Burns 23 (2): 151 - 153

Gupta, M., Bansal, M., Gupta, A., \& Goil, P. (1996). The kerosene tragedy of 1994, an unusual epidemic of burns: epidemiological aspects and management of patients, Burns 22 (1): 3-9

Hudson, D., Rode, H., \& Bloch, C. (1994). Primus stove burns in Cape Town: a costly preventable injury, Burns 20 (3): $251-252$

Kalayi, G. \& Muhammad, I. (1994). Clothing burns in Zaria, Burns 20 (4): 356 - 359

Kildal, M., Willebrand, M., Anderson, G., Gerdin, B. \& Ekselius, L. (2004). Personality Characteristics and Perceived Health Problems after Burn Injury. Journal of Burn Care and Rehabilitation, 25(3): 228-235

Lakhoo, K . (1995). Management of burns in childhood. Trauma and Emergency Medicine, 12(4): $127-131$

Lari, A., Panjeshahin, M., Talei, A., Rossignol, A. \& Alaghehbandan, R. (2002). Epidemiology of Childhood Burn Injuries in Fars Province, Iran, Journal of Burn Care \& Rehabilitation, 23 (1): 39 - 45

McLoughlin, E. \& McGuire, A. (1990). The Causes, Cost and Prevention of Childhood Burn Injuries, American Journal Disease in Childhood 144: 677 - 683

Mugenda, O. M. and Mugenda, A. G. (2003).Research Methods: Quantitative and Qualitative

Peck, M., Kruger, G., van der Merwe, A., Godakumbura, W. \& Ahuja, R. (2008). Burns and fires from non-electric domestic appliances in low and middle income countries, Burns 34: $303-311$ 
Pham, T. N., Cancio, L. C., \& Gibran, N. S. (2008). American Burn Association practice guidelines: Burn shock resuscitation. Journal of Burn Care \& Research, 29(1), 257266

Saunders, M., Lewis, P. and Thornhill, A. (2009). Research methods for business students. (5th Edition). London: Prentice Hall.

Van Niekerk, A. (2007). Paediatric Burn Injuries in Cape Town, South Africa. Context, Circumstances and Prevention, Karolinska Institutet, Stockholm

Van Niekerk, A., Rode, H. \&Laflamme, L. (2004).Incidence and patterns of childhood burn injuries in the Western Cape, South Africa. Burns, 30: 341-347

Werneck, G. \& Reichenheim, M. (1997). Paediatric burns and associated risk factors in Rio de Janeiro, Brazil, Burns 23 (6): 478 - 483 